\title{
RECURRENCE OF THYROID DISORDERS IN PATIENTS WHO UNDERWENT SUBTOTAL THYROIDECTOMY FOR MNG
}

\author{
Sherine E. $K^{1}$, Naseer C. P2, Gopi E. V ${ }^{3}$ \\ ${ }^{1}$ Assistant Professor, Department of General Surgery, Government Medical College, Kozhikode. \\ 2Junior Resident, Department of General Surgery, Government Medical College, Kozhikode. \\ 3Professor, Department of General Surgery, Government Medical College, Kozhikode.
}

\begin{abstract}
BACKGROUND

Subtotal thyroidectomy is the preferred procedure currently done in our institution for multinodular goitre. However, many surgeons prefer near-total thyroidectomy for this condition as the recurrence of Multinodular goitre is less with this procedure. The main advantage of subtotal thyroidectomy is that the post-operative complications like hypothyroidism, hypocalcaemia and recurrent laryngeal nerve palsy are found to be less with this procedure. In this study, we assess the hypothesis that Subtotal thyroidectomy is not associated with increased risk of recurrence as compared to Near-total thyroidectomy and Total thyroidectomy in cases of benign thyroid disease, multinodular goitre.
\end{abstract}

\section{MATERIALS AND METHODS}

We conducted a retrospective study among patients who underwent subtotal thyroidectomy in Govt. Medical College, Calicut during a 5-year period from 2008 to 2012 . We collected data from the record library and contacted them through letter. A total of 108 patients were included. Then, detailed history taking, physical examination and relevant investigations were done.

\section{RESULTS}

Postoperative USG and FNAC showed 3 cases of recurrence, that is $2.8 \%$. Postoperative functional status shows that $21 \%$ remained euthyroid and about 79\% were hypothyroid. No cases of hypocalcaemia or recurrent laryngeal nerve palsy were reported.

\section{CONCLUSION}

There is no increased risk among these subjects considering recurrence, but had advantage of lesser complications. So it concludes that subtotal thyroidectomy is a better procedure for benign thyroid diseases compared to total thyroidectomy and is not with increased risk of recurrence.

\section{KEYWORDS}

Multinodular Goitre, Thyroidectomy, Euthyroid, Hypothyroid, Hypocalcaemia, Recurrent Laryngeal Nerve.

HOW TO CITE THIS ARTICLE: Sherine EK, Naseer CP, Gopi EV. Recurrence of thyroid disorders in patients who underwent subtotal thyroidectomy for MNG. J. Evolution Med. Dent. Sci. 2017;6(89):6200-6203, DOI: 10.14260/jemds/2017/1348

BACKGROUND
Multinodular goitre (MNG) is a common disease of thyroid gland worldwide and surgery is a desired option of treatment for this disease. Common modes of surgeries are subtotal thyroidectomy (STT), near-total thyroidectomy (NTT) and total thyroidectomy (TT).

Subtotal thyroidectomy is the choice of surgery for most of benign thyroid disorders as the post-operative complications are less with this procedure. Post-operative hormone replacement is usually not needed following subtotal thyroidectomy. Near-total thyroidectomy is the preferred option of surgery for many surgeons because of lower post-operative recurrence. Total thyroidectomy is also a surgical procedure frequently practised in our setup recently. No remnant thyroid tissue is left in total thyroidectomy and thus postoperative complication rates and

'Financial or Other Competing Interest': None.

Submission 21-10-2017, Peer Review 29-10-2017,

Acceptance 04-11-2017, Published 13-11-2017.

Corresponding Author:

Dr. Sherine E. K,

Assistant Professor,

Department of General Surgery,

Government Medical College,

Kozhikode.

E-mail:sherinesajeeth@yahoo.com

DOI: $10.14260 /$ jemds $/ 2017 / 1348$

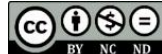

recurrent laryngeal nerve palsy are high compared to subtotal thyroidectomy and near-total thyroidectomy.

\section{Historical Aspects}

The thyroid gland was discovered by Wharton in 1656. Its function was, however, not known. In 1874, Gull described thyroid hypofunctioning in man. Magnus Levy reported increased basal metabolic rate in patients with hyperthyroidism.(1)

Although thyroid surgery is now routinely performed for the treatment of thyroid neoplasm, multinodular goitre and some forms of hyperthyroidism, it was formerly a precious undertaking that even the world's greatest surgeons were reluctant, many in fact condemned. The first thyroidectomy was reportedly performed by a Moorish Surgeon Albucasis.(1)

Lister's discovery of antisepsis in 1867 and the development and use of haemostatic forceps in European clinics heralded a new era of thyroid surgery. In to this arena enters the Professor of Surgery in Berne, Theodor Kocher, the pioneer in thyroid surgery. He performed his first thyroidectomy in 1872 . Initially the mortality rate was $13 \%$ and by 1898 it was brought down to less than $1 \%$. His mean perfect results were achieved by careful attention to control of blood loss and protection of the parathyroid glands.(1) $\mathrm{He}$ also emphasised on the avoidance of recurrent laryngeal nerve injury. 
At the end of his career, he had performed more than 5000 thyroidectomies with the amazing low mortality of only one percent. (1)

In addition to his contribution to surgery, Kocher also recognised thyroid insufficiency following thyroidectomy. He had given a detailed description about the post-operative thyroid insufficiency. Theodor Kocher is considered to be the father of thyroid surgery.(2)

In 1891, Murray, Gley and Varsale demonstrated improvement in a myxoedematous patient after the administration of the sheep thyroid extract. Bartman established the presence of high iodine content in thyroid tissue in 1896. In 1915, Kendall isolated thyroxine and in 1927, Harrington and Bargery synthesised it. Triiodothyronine (T3) was detected, isolated and synthesised by Gross and Pitt Rivers in 1952.(1) The availability of radioiodine and the introduction of chromatographic techniques have contributed significantly to a clearer understanding of thyroid physiology.(2) With the surgical techniques of thyroidectomy established, knowledge of the metabolic function and regulation of thyroid provided the base for further effective treatment of its disorders.(2)

\section{Adult Surgical Anatomy}

A normally developed adult thyroid is a bilobed structure that lies next to the thyroid cartilage in a position anterior and lateral to the junction of larynx and trachea. In this position, the thyroid encircles about $75 \%$ of the diameter of the junction of the larynx and the upper part of the trachea. The two lateral lobes are joined at the midline by an isthmus, whose superior edge is situated at or just below the cricoid cartilage. The pyramidal lobe represents the most distal portion of the thyroglossal duct and in an adult may be a prominent structure that can extend from the midline of the isthmus as far cephalad as the hyoid bone.(2)

A thin layer of connective tissue surrounds the thyroid. This tissue is part of the fascial layer that invests the trachea.(2) This fascia is different from the thyroid capsule, and during surgery it can easily be separated from the capsule, whereas the true capsule of the thyroid cannot. This fascia coalesces with thyroid capsule posteriorly and laterally to form a suspensory ligament known as ligament of Berry. The ligament of Berry is closely attached to the cricoid cartilage and has the important surgical implication because of its relationship to the recurrent laryngeal nerve.(2)

\section{Physiology of the Thyroid Gland}

The thyroid gland is responsible of the production of two families of metabolic hormones, the thyroid hormonesthyroxine (T4) and triiodothyronine (T3), and the calciumregulating hormone calcitonin.(3) The spherical thyroid follicular unit is the important site of thyroid hormone production. The thyroid follicle is made up of single layer of cuboidal follicular cells that encompass a central depository of colloid filled mostly with thyroglobulin (TG), the protein within which T4 and T3 are synthesised and stored. Each follicle is surrounded by a rich network of capillaries that interdigitate among the multiple follicular units continued within normal thyroid matrix.(3)

C cells, derived from the neural crest, migrate into the thyroid during embryologic development.(2) These cells rest in a parafollicular position, predominantly in the upper lobe of each thyroid, $\mathrm{C}$ cells are responsible for production of the hormone calcitonin, which has important regulatory in calcium metabolism.(3)

\section{Thyroid Surgeries}

Terminology for thyroid surgery is inconsistent in the literature.(4) Total thyroidectomy involves division of all thyroid tissue between the entrance of the recurrent laryngeal nerves bilaterally at the ligament of Berry and results in complete removal of all visible thyroid tissue.(5) Near-total thyroidectomy involves complete dissection on one side while leaving a remnant of thyroid tissue laterally on the contralateral side, which incorporates the parathyroid and leaves less than $1 \mathrm{~g}$ of tissue adjacent to the recurrent laryngeal nerve at the ligament of Berry. Subtotal thyroidectomy leaves a rim of thyroid tissue bilaterally to ensure parathyroid viability and avoid entrance of the recurrent laryngeal nerves into the larynx. ${ }^{(5,6)}$

If a subtotal or total thyroidectomy is planned, the same approach is taken for anaesthesia, patient position, and site preparation.(7) When obtaining consent, additional discussion should include the risk of hypoparathyroidism, as all four parathyroid glands will be at risk during this procedure. In addition, both recurrent laryngeal nerves are at risk, which may increase the potential for nerve injury and although rare, bilateral nerve injury is a possibility. $(5,6)$

One should perform the operation on the most abnormal side of the thyroid first, so that if the nerve is inadvertently injured or invaded by thyroid cancer, a less extensive procedure can be performed on the opposite side to ensure the contra lateral nerve is preserved (5). Bilateral recurrent laryngeal nerve palsy should be avoided at all costs, as this often requires a tracheostomy to protect the patient's airway.(7) Patients should be aware that after total or near thyroidectomy, they would require lifelong thyroid hormone replacement.(8)

If the underlying thyroid condition is benign, the isthmus can still be divided. This creates more room in the operative field and dissection of the posterior surface of the thyroid off the trachea enables better mobilisation of the gland interiorly. $(5,9)$

If the thyroidectomy is being performed for a proven or potential underlying malignancy, isthmus division should be avoided and the entire thyroid excised en bloc.(10) A neartotal thyroidectomy leaves less than $1 \mathrm{~g}(1 \mathrm{~cm})$ of thyroid tissue on one side of the neck. It is performed when a total thyroidectomy is planned, but a minute portion of thyroid is purposely left in situ, in close proximity to the recurrent laryngeal nerve or parathyroid gland.(11)

\section{Postoperative management}

Postoperative monitoring of thyroid and parathyroid function is extremely important. The surgeon is obligated to evaluate and inform the patient and referring physician of the details of the resection and its expected impact on postoperative function.(12) A calcium assay is performed within 24 hours of surgery. If no signs of hypocalcaemia are present, particularly if the surgeon has visualised the glands during surgery, no calcium supplementation may be necessary. If symptoms occur or if the surgeon is concerned about the patient's parathyroid status, daily supplements of 1500 to $3000 \mathrm{mg}$ of elemental calcium may be started.(13,14)

If the patient was euthyroid before surgery, it is reasonable to expect that replacement may not be needed for 
at least 10 days, even after total thyroidectomy.(15) This allows time for complete evaluation of the specimen by pathology. Thyroid replacement generally requires a daily dose of 1.6 microgram $/ \mathrm{kg}$ of levothyroxine. Most endocrinologists believe that the levothyroxine dose needs to be adjusted to keep TSH levels at low normal values after resection for cancer or suppressive therapy.(5)

There are many clinical trials comparing complications and recurrence of thyroid disease from subtotal thyroidectomy, near-total thyroidectomy, and total thyroidectomy.(15) In this study, we focus on the recurrence rate of benign thyroid disease and postoperative complications in case of patients who underwent subtotal thyroidectomy in our institution.

\section{MATERIALS AND METHODS}

We conducted a retrospective study on recurrence and postoperative complications in patients who had undergone subtotal thyroidectomy in Govt. Medical College, Calicut during the five-year period from $01 / 01 / 2008$ to $31 / 12 / 2012$. Objectives were to assess the recurrence and postoperative complications like hypothyroidism, hypocalcaemia and recurrent laryngeal nerve palsy and also to assess the feasibility of subtotal thyroidectomy as compared to neartotal thyroidectomy and total thyroidectomy.

Patients who underwent subtotal thyroidectomy for Multinodular goitre during the period of 01.01.2008 to 31.12.2012 are included in the study. Patients who were not willing to participate in the study are excluded. Patients with pathological evidence of thyroid cancer and patients with family history of thyroid cancer are also excluded.

We collected data on age, sex, details of thyroid disease and details of thyroid surgery done and followed up the patients by calling them with letters for review. Then, we conducted detailed clinical examination of the patients and investigated them with Free T3, Free T4, TSH and USG neck to rule out recurrence. Those who had thyroid nodule in USG were subjected to FNAC from the nodule. The data thus collected were analysed to prove the hypothesis that subtotal thyroidectomy is not associated with increased risk of recurrence.

\section{RESULTS}

\section{Preoperative Analysis}

A total of 204 cases were contacted and 108 persons responded. All of them were preoperatively diagnosed to have benign goitre excluding proven or suspicious malignancy. All clinically presented as neck swelling, two of them had hoarseness, none had dysphagia or dyspnoea. All cases were evaluated by ENT Department and showed no recurrent laryngeal nerve palsy.

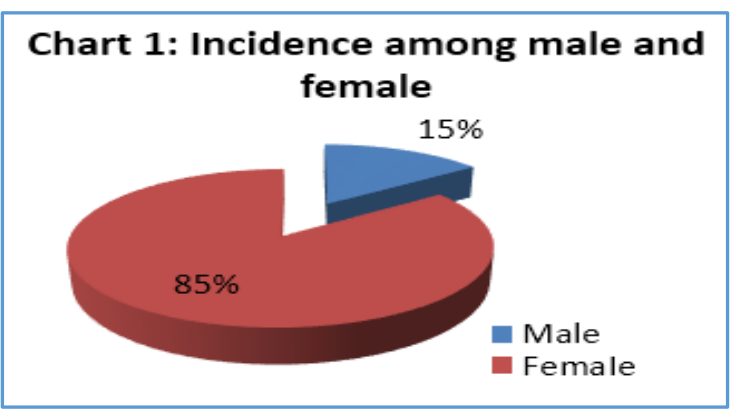

Total number of cases followed up were 108. Of these, 92 (85\%) were female and $16(15 \%)$ were male. The thyroid disorders are more common among females in these areas. Preoperative functional status of thyroid hormone showed 76 subjects were euthyroid; 28 subjects were hypothyroid and 4 subjects were hyperthyroid. All hypothyroid cases were on thyroxin replacement and hyperthyroid cases were on antithyroid drugs.

\section{Chart 2: Thyroid function}

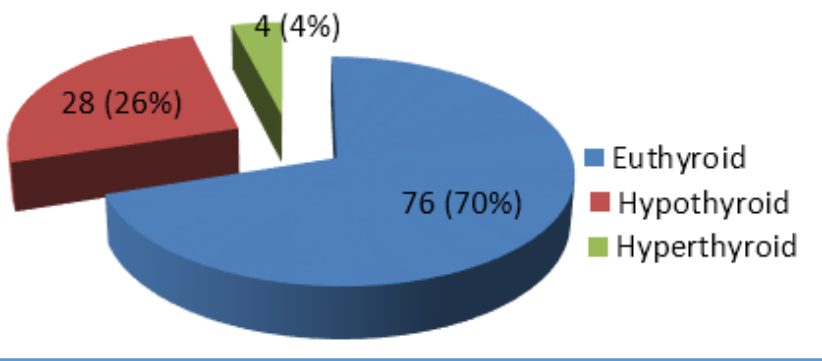

Preoperative FNAC was performed in all subjects, the results were: 97 cases (89.8\%) were suggestive of nodular colloid goitre and 11 cases (10.2\%) were goitre with thyroiditis. All cases were subjected to imaging by ultrasonography and the results showed about $80 \%$ were suggestive of multinodular goitre and about $20 \%$ cases were solitary nodule thyroid.

\begin{tabular}{|c|c|c|}
\hline FNAC & Frequency & Percent \\
\hline Nodular colloid & 97 & 89.8 \\
\hline Thyroiditis & 11 & 10.2 \\
\hline Total & 108 & 100 \\
\hline \multicolumn{2}{|r|}{ Table 1. Preoperative FNAC } \\
\hline
\end{tabular}

\section{Postoperative Analysis}

Out of the total 108 patients, 3 patients had recurrence of goitre which constitutes $2.8 \%$ of total patients studied. Out of 79 Multinodular goitre patients, $76(96.2 \%)$ had no swelling and 3 (3.8\%) had recurrent thyroid swelling. Among 29 Solitary thyroid nodule patients and 11 thyroiditis patients, none had recurrence.

All recurrent cases were nodular colloid goitre on histopathology. No patients were reported to have postoperative recurrent laryngeal nerve palsy or hypocalcaemia.

\begin{tabular}{|c|c|c|c|}
\hline \multirow{2}{*}{ Pre-op } & \multicolumn{2}{|c|}{ Post-op } & \multirow{2}{*}{ Total } \\
\cline { 2 - 3 } & No Swelling & $\begin{array}{c}\text { Thyroid } \\
\text { Swelling }\end{array}$ & \\
\hline MNG & $76(96.2 \%)$ & $3(3.8 \%)$ & $79(100 \%)$ \\
\hline SNT & $29(100 \%)$ & $0(0 \%)$ & $29(100 \%)$ \\
\hline Total & $105(97.2 \%)$ & $3(2.8 \%)$ & $108(100 \%)$ \\
\hline
\end{tabular}

Table 2. Comparison of Pre- and Post-operative Status of Thyroid Swelling

Postoperative functional status showed about $21 \%$ still remained euthyroid and about $79 \%$ were hypothyroid. Among 76 euthyroid patients, 36.8\% (28) remained as euthyroid and $63.2 \%$ (48) became hypothyroid. Among 28 hypothyroid patients, 3.6\% (1) became euthyroid and $96.4 \%$ (27) remained as hypothyroid. Among 4 hyperthyroid 
patients, no one became euthyroid and $4(100 \%)$ became hypothyroid. Postoperatively, 51 patients (47.2\%) were continuing on thyroxine.

\begin{tabular}{|c|c|c|c|}
\hline $\begin{array}{c}\text { Pre-op } \\
\text { functional } \\
\text { Status }\end{array}$ & Post-op Functional Status & \multirow{2}{*}{ Total } \\
\cline { 2 - 3 } & Euthyroid & Hypothyroid & \\
\hline Euthyroid & $28(36.8 \%)$ & $48(63.2 \%)$ & $76(100 \%)$ \\
\hline Hypothyroid & $1(3.6 \%)$ & $27(96.4 \%)$ & $28(100 \%)$ \\
\hline Hyperthyroid & $0(0 \%)$ & $4(100 \%)$ & $4(100 \%)$ \\
\hline Total & $\mathbf{2 9}(\mathbf{2 6 . 9 \% )}$ & $\mathbf{7 9}(\mathbf{7 3 . 1} \%)$ & $\begin{array}{c}\mathbf{1 0 8} \\
\mathbf{1 0 0} \%)\end{array}$ \\
\hline Table 3. Comparison of Thyroid Functional Status \\
\hline
\end{tabular}

\section{DISCUSSION}

In our study, the focus is on the rate of recurrence among people who underwent subtotal thyroidectomy. This is by mainly through clinical examination then they may be subjected to radiological histological investigations. The study also includes the major complications of subtotal thyroidectomy. In case of subtotal thyroidectomy, a part of thyroid tissue is kept near the Recurrent laryngeal nerve. This is to avoid complications like nerve palsy and hypocalcaemia.

Even though recurrence rate is high compared to total thyroidectomy, other complications like hypocalcaemia and Recurrent laryngeal nerve palsy is less. In case of total thyroidectomy, the transient and permanent hypocalcaemia and the rate of Recurrent laryngeal nerve palsy are high. Postoperative permanent hypothyroidism is another factor which is decided by the choice of surgery. Those with features of hypothyroidism are more in complete procedures. Those who need thyroxine after surgery are also more in total thyroidectomy.

A study conducted by Young et al showed the recurrence rate of about $6 \%$ and those with transient parathyroid deficiency of up to $24 \%$ as compared to up to $9 \%$ in cases of subtotal thyroidectomy. In an Italian study comparing subtotal thyroidectomy and total thyroidectomy, the result showed recurrence rate more in case of subtotal thyroidectomy, but low postop complications.(18) In this study, almost all subjects needed thyroxine replacement who underwent total thyroidectomy. On comparing this data with subtotal thyroidectomy, less patients needed thyroxine following surgery. In both these studies, permanent recurrent laryngeal nerve palsy and permanent hypocalcaemia are similar in both groups.

\section{CONCLUSION}

In our study, my observation is that the recurrence rate of thyroid disorder is only $2.78 \%$ in those who underwent subtotal thyroidectomy during followup of cases. The patients who required lifelong thyroxin were less. The subjects who became hypothyroid from euthyroid status following subtotal thyroidectomy were only $63 \%$ and $37 \%$ remained as euthyroid itself. No one in group had permanent hypocalcaemia or Recurrent laryngeal nerve palsy. Here there is no increased risk among these subjects considering recurrence, but had advantage of lesser complications.
So subtotal thyroidectomy is a better procedure for benign thyroid diseases compared to total thyroidectomy and risk of recurrence is less.

\section{REFERENCES}

[1] Lydiatt DD, Bucher GS. Historical vignettes of the thyroid gland. Clin Anat 2011;24(1):1-9.

[2] Moore KL, Dalley AF, Agur AMR. Clinically oriented anatomy. Lippincott Williams \& Wilkins, 2013.

[3] Spitzweg C, Heufelder AE, Morris JC. Thyroid iodine transport. Thyroid 2000;10(4):321-30.

[4] Josef FE, Bland KI, Callery MP. (eds). Mastery of surgery. Lippincott Williams \& Wilkins, 2006.

[5] David SC, Townsend CM. Sabiston textbook of surgery: The biological basis of modern surgical practice. Saunders, 2002.

[6] Kohl BA, Schwartz S. Surgery in the patient with endocrine dysfunction. Med Clin North Am 2009;93(5):1031-47.

[7] Lal G, Ituarte P, Kebebew E, et al. Should total thyroidectomy become the preferred procedure for surgical management of Graves disease? Thyroid 2005;15(6):569-74.

[8] Weber KJ, Solorzano CC, Lee JK, et al. Thyroidectomy remains an effective treatment option for Graves disease. Am J Surg 2006;191(3):400-5.

[9] Walsh RM, Watkinson JC, Franklyn J. The management of the solitary thyroid nodule: a review. Clin Otolaryngol Allied Sci 1999;24(5):388-97.

[10] Gough IR, Wilkinson D. Total thyroidectomy for management of thyroid disease. World J Surg 2000;24(8):962-5.

[11] Bellantone R, Lombardi CP, Bossola M, et al. Total thyroidectomy for management of benign thyroid disease: review of 526 cases. World J Surg 2002;26(12):1468-71.

[12] Bron LP, O’Brien CJ. Total thyroidectomy for clinically benign disease of the thyroid gland. $\mathrm{Br} \mathrm{J}$ Surg 2004;91(5):569-74.

[13] Pisanu A, Montisci A, Cois A, et al. Surgical indications for toxic multinodular goiter. Chir Ital 2005;57(5):597-606.

[14] Ladenson PW, Levin AA, Ridgway EC, et al. Complications of surgery in hypothyroid patients. Am J Med 1984;77(2):261-6.

[15] Castro MR, Gharib H. Continuing controversies in the management of thyroid nodules. Ann Intern Med 2005;142(11):926-31.

[16] Braga M, Cavalcanti TC, Collaco LM, et al. Efficacy of ultrasound guided fine-needle aspiration biopsy in the diagnosis of complex thyroid nodules. J Clin Endocrinol Metab 2001;86(9):4089-91.

[17] Sabel MS, Staren ED, Gianakakis LM, et al. User of fineneedle aspiration biopsy and frozen section in the management of the solitary thyroid nodule. Surgery 1997;122(6):1021-6.

[18] Sosa JA, Bowman HM, Tielsch JM, et al. The importance of surgeon experience for clinical and economic outcomes from thyroidectomy. Ann Surg 1998;228(3):320-30. 